\title{
Removal effect on Mesocyclops leukarti and mutagenicity with chlorine dioxide
}

\author{
ZUO Jin-long ${ }^{1}$, CUI Fu-yi ${ }^{1, *}$, QU Bo ${ }^{2}$, ZHU Gui-bing ${ }^{1,2}$ \\ (1. School of Municipal and Environmental Engineering, Harbin Institute of Technology, Harbin 150090, China. E-mail: cuifuyi@public. hr. hl. cn; \\ mdjzj1@163.com; 2. Research Center for Eco-Environmental Sciences, China Academy of Sciences, Beijing 100085, China)
}

\begin{abstract}
Mesocyclops leukarti of zooplankton propagates excessively in eutrophic water body and it cannot be effectively inactivated by the conventional drinking water treatment process. In order to tackle this problem, a study of removal effect on Mesocyclops leukarti with chlorine dioxide in a waterworks was performed. The results showed that Mesocyclops leukarti could be effectively removed from water by $1.0 \mathrm{mg} / \mathrm{L}$ chlorine dioxide preoxidation combined with the conventional drinking water treatment process. Higher oxidizability and molecular state of chlorine dioxide in water is the key to the inactivation of Mesocyclops leukurti. The chlorite, disinfection by-products (DBPs) of chlorine dioxide, was stable at $0.45 \mathrm{mg} / \mathrm{L}$, which is lower than that critical value of the USEPA. GC-MS examination showed that the quantity of organic substance in the water treated by chlorine dioxide obviously decreased. Ames test further revealed that the mutagenicity was reduced by chlorine dioxide with respect to prechlorine. The propagation of Mesocyclops leukarti can be inactivated effectively and safely by chlorine dioxide pre-oxidation.
\end{abstract}

Keywords: chlorine dioxide; disinfection by-products (DBPs); Mesocyclops leukarti; preoxidation; mutagenicity

\section{Introduction}

The eutrophication of surface water is a worldwide problem, which is increasing in significance (Ma and Liu, 2002). Mesocyclops leukarti, a kind of Cyclops, is a waterborne animal that excessively propagates in eutrophic reservoirs and fresh lakes in China. Some of them are sources of drinking water supply, e.g., Dahuofang Reservoir in Liaoning Province, East Taihu Lake in Jiangsu Province, Miyun Reservoir, Beijing, etc. Cyclops cannot be effectively inactivated by the conventional disinfection due to its stronger resistance to oxidation (Cui et al., 2002). In addition, the mobility of Cyclops makes it easily penetrate the sand filters into the plant reservoirs, and even into the municipal service pipes. In recent years, there have been several contamination accidents with Cyclops appearing in the municipal service pipes in several cities in China (Xing, 2004). So how to remove Mesocyclops leukarti is a currently growing problem in the production of drinking water.

Adult Cyclops can bring disease to consumers because it is intermediate host of some diseases. Olajide and Sridhar (1987) proposed that Guineaworm disease could be effectively controlled by killing the Cyclops (intermediate host). Lupi et al. (1994) considered that flocculation and sand filtration processes were insufficient to remove zooplankton normally present in surface water. It was reported that the rotifer abundance would be reduced from $20-300$ ind./L to $0-5$ ind./L in drinking water by oxidation with $2.5-3 \mathrm{mg} / \mathrm{L}$ of chlorine for $20 \mathrm{~min}$ (Bernhardt and Lusse, 1989). Mitcham et al. (1983) found that ammonia-chlorine was more effective against $C y c l o p s$ but less effective against Cladocera.
At present, conventional process is still the main technique for drinking water treatment in China. Cyclops is inactivated or killed by prechlorination and removed from water by sedimentation and filtration processes. For example, Cyclops is inactivated by prechlorination with $2.5 \mathrm{mg} / \mathrm{L}$ in Shijiazhuang Waterworks. However, there are still a few activated Cyclops after filtration (Xing, 2004). Furthermore, prechlorination would reduce the drinking water security for increasing the halomethane content in treated water (Gibbonsa and Laha 1999; Li et al., 1996). Therefore, it is essential to develop a more effective and safe removal technique. As a powerful substitute or a supplemental disinfectant for chlorination (Narkis, 1995), $\mathrm{ClO}_{2}$ can eliminate bad odor and oxidize ferrous, manganous ions (Aieta and Berg, 1986). A smaller dosage and less reaction time is required for $\mathrm{ClO}_{2}$ to produce the same disinfection effect. In view of these characteristics, chlorine dioxide was selected and investigated in this study, which aimed to: (1) detcrmine the better adding doses for inactivated Mesocyclops leukarti; (2) investigate the disinfection by-products in water treated by chlorine dioxide; (3) study the mutagenicity and security after preoxidation.

\section{Materials and methods}

\subsection{Raw reservoir water}

Binxian Waterworks is located in the northeast part of China (Heilongiiang Province), where an eutrophic reservoir serves as a unique drinking water source. Microscopic observations showed that the species of Cyclops in this reservoir is Mesocyclops leukarti. The drinking water treatment process is shown in Fig.1. The raw water quality is: average 


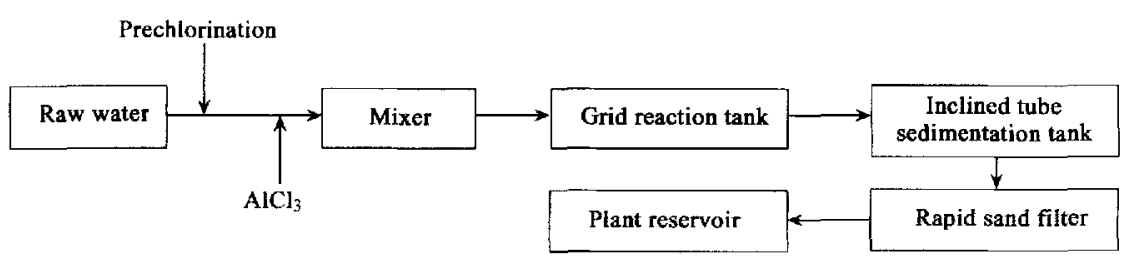

Fig.1 Chart of drinking water treatment processes in Binxian Waterworks

water temperature $15-19^{\circ} \mathrm{C}$; turbidity $10-30$ NTU; $\mathrm{COD}_{\mathrm{Mn}} 5.68 \mathrm{mg} / \mathrm{L} ; \mathrm{pH} 7.3-7.5$; algae density $(2.1-$ 2.6) $\times 10^{6}$ cells/L and Mesocyclops leukarti density 20 ind. $/ \mathrm{L}$.

\subsection{Experimental equipments}

Chlorine dioxide gas generator is manufactured by ourselves. Componential analysis of chlorine dioxide gas is listed in Table 1 by using the following instruments: OF-3 type ozone generator (Shanghai Environmental Protection Company); XSB-1A inverted series biological microscope (Alltion Wuzhou Company); QP5050A type gas chromatograph-mass spectrometer (Shimadzu, Japan). TA100 and TA98 strains without metabolic activation $\mathrm{S} 9$ were provided by Harbin Medical University. The $\mathrm{pH}$ and temperature measurements were conducted by WTW $\mathrm{pH} / \mathrm{Oxi} 340 \mathrm{i}$ (Germany) with the $\mathrm{pH}$ and temperature probe (pH-Electrode SenTix 4).

Table 1 Componential analysis of chlorine dioxide gas

Chemical composition Chlorine dioxide Chlorine Chlorite Chlorate $\begin{array}{lllll}\text { Composition, } \% & 85.6 & 7.4 & 5.1 & 1.9\end{array}$

\subsection{Methods}

All the analyses were performed according to the standard methods (Chinese EPA, 1997). The experimental and full-scale studies were carried out in Binxian Waterworks.

Mesocyclops leukarti was determined by microscopic activated count method, and the changes of Mesocyclops leukarti number between raw water and treated water were investigated.

Chlorine dioxide was generated by mixing hydrochloric acid solution $(23 \% \mathrm{w} / \mathrm{w})$ and sodium chlorite solution $(25 \% \mathrm{w} / \mathrm{w})$ in a weight ratio $1: 1$. More than $300 \%$ of the stoichiometric acid was demanded so as to improve the efficiency and obtain a lower $\mathrm{Cl}_{2}, \mathrm{ClO}_{2}^{-}$and $\mathrm{ClO}_{3}^{-}$production. Componential analysis of chlorine dioxide was measured by iodimetry.

Raw water and treated water by chlorine dioxide or chlorine preoxidation were sampled by $250 \mathrm{~L}$ respectively. Organic substances in water samples were enriched with XAD-2 resins about $5 \mathrm{~h}$ and then were eluted with about $60 \mathrm{ml}$ of methanol. The methanol samples containing organic substances were concentrated to about $1 \mathrm{ml}$ with K-D concentrator. The concentrated samples were examined in duplicate with gas chromatograph-mass spectrometer (GC-MS) and tested by Ames test. The GC-MS analytical conditions were: DB-5 capillary column $(30 \mathrm{~m}, 0.25 \mathrm{~mm}$ i.d., $0.25 \mu \mathrm{m}$ thickness), and the carrier gas (He) flow rate was at $1.2 \mathrm{ml} / \mathrm{min}$. The oven temperature was kept constant at $35^{\circ} \mathrm{C}$ for $2 \mathrm{~min}$ and then ramped to $160^{\circ} \mathrm{C}$ at a rate of $10^{\circ} \mathrm{C} / \mathrm{min}$, further to $250^{\circ} \mathrm{C}$ at a rate of $20^{\circ} \mathrm{C}$ $/ \mathrm{min}$ and held for $12 \mathrm{~min}$. The injector temperature was $240^{\circ} \mathrm{C}$. The ionization mode was electron impact (EI).

The Ames test was carried out according to a standard plate incorporation assay (USEPA, 1983). TA98 detects frame shift mutagens, whilst TA100 detects base-pair substitution mutagens. In this work it was done without in vitro microsomal activation (S9 mix) because most of the natural mutagens act directly and do not require activation (Haider et al., 2002). Concentrated water samples (concentration factor 1: 10000) were tested in triplicate with four doses: 100 , 300,500 and $700 \mu \mathrm{l}$. Results were expressed as mutation ratio (MR), calculated as the number of colonies on test plates/number of colonies on control plates (USEPA, 1983).

\section{Results and discussion}

\subsection{Dosage of $\mathrm{ClO}_{2}$ on removal efficiency of Mesocyclops leukarti in lab}

Chlorine dioxide $\left(\mathrm{ClO}_{2}\right)$ was added into a given volume of $10 \mathrm{~L}$ reservoir water to study removal efficiency of Mesocyclops leukarti (Fig.2).

It can be seen that the inactivation effects of $\mathrm{ClO}_{2}$ on Mesocyclops leukarli were strengthened gradually

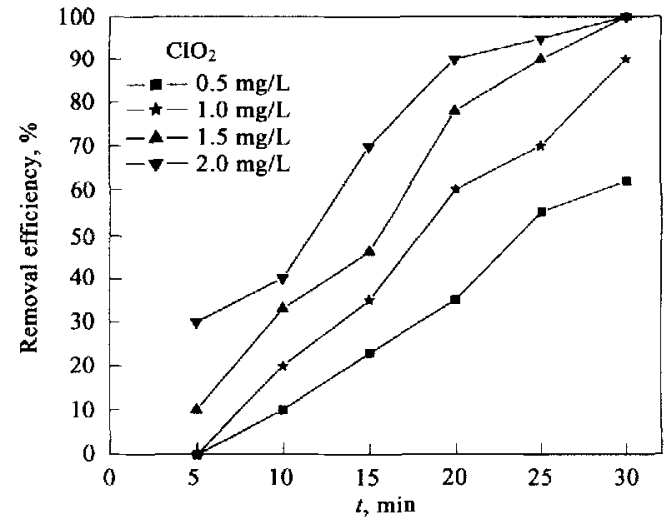

Fig.2 Removal efficiency of Meserrotops leukuri by yarious $\mathrm{ClO}_{2}$ dosages

Conditions: Mesocyclops: lrukurli density 20 ind./L; $\mathrm{pH} 7.4, T$ $18^{\circ}:$ 
as $\mathrm{ClO}_{2}$ dosage increased. $100 \%$ inactivated rate of Mesocyclops leukarti could be obtained by $1.5 \mathrm{mg} / \mathrm{L}$ of chlorine dioxide contacting for $30 \mathrm{~min}$. It is worth noting that the removal rate of Mesocyclops leukarti was almost zero when oxidant dosage and react time was $0.5-1.0 \mathrm{mg} / \mathrm{L}$ and $5 \mathrm{~min}$, respectively.

The substance in raw water such as $\mathrm{COD}_{\mathrm{M}}$ and algae would also consume oxidants. It can be seen that Mesocyclops leukarti could not be effectively inactivated with lower dose of oxidants and shorter react time. The adequate oxidant is a key factor in the process of inactivating Mesocyclops leukarti.

\subsection{Dosage of $\mathrm{ClO}_{2}$ on removal efficiency of Mesocyclops leukarti in full-scale study}

The chlorine dioxide was added into grid reaction tank together with coagulant, $15 \mathrm{mg} / \mathrm{L}$ of $\mathrm{AlCl}_{3}$, and chlorine dioxide dosage ranged from 0 to $1.0 \mathrm{mg} / \mathrm{L}$ in full-scale study. The results are shown in Fig.3. It can be seen that the removal effects were strengthened gradually with the increase of the dose of $\mathrm{ClO}_{2} .100 \%$ removal with treated water through the sand filter could be reached by $1.0 \mathrm{mg} / \mathrm{L}$ of $\mathrm{ClO}_{2}$. In addition, $10 \%$ and $40 \%$ of removal rate might be attained by sedimentation and filtration process under no chlorine dioxide dosing condition, respectively. This means that Mesocyclops leukarti can be partially removed from water by single clarification process

The vitality of Mesocyclops leukarti in raw water

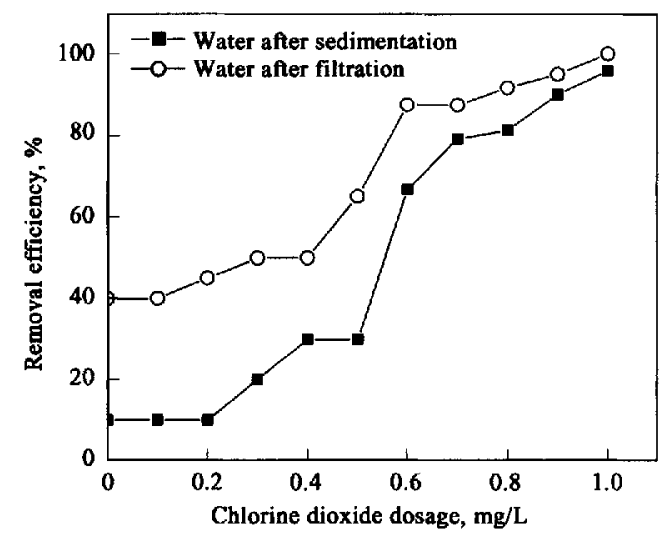

Fig.3 Removal effect on Mesocyclops leukurli by different chlorine dioxide dosages

was found to be distinct, namely, the activity of larve and senile Mesocyclops leukarti were obviously weaker than that of mature Mesocyclops leukarti. Therefore, part of weaker Mesocyclops leukarti can deposit into the floc in sedimentation process or be captured by sand filter. However, the removal effect on Mesocyclops leukarti by single clarification process was finite because Mesocyclops leukarti with stronger vitality might still penetrate the sand filter. The further removal effect depend on the inactivation of oxidant preoxidation.

Based on the above experimental results, Mesocyclops leukarti can be inactivated and its vitality can be greatly weakened with the increase of dosing $\mathrm{ClO}_{2}$. Similarly, larve and senile Mesocyclops leukarti were effectively removed from water by subsequent clarification process. The results showed that the conventional processes, sedimentation and filtration play an important role in removing Mesocyclops leukarti. And the inactivation of Mesocyclops leukarti by preoxidation with adequate available oxidant was also essential to ensure the security of drinking water. Mesocyclops leukarti can be thoroughly removed from water by the cooperation of oxidant preoxidation and clarification process.

\subsection{By-products of $\mathrm{ClO}_{2}$}

An effective method to control chlorine by-products in drinking water is to use oxidantsozone, chloramines or chlorine dioxide for that they may all form non-chlorinated disinfection by-products (DBPs). For chlorine dioxide, there are no reactions with humic acids to form trihalomethanes (Lykins and Griese, 1986). However, the inorganic by-products such as chlorite are formed and they also have human health risk implications (USEPA, 1998).

Fig.4 shows the concentration of residual prechlorine dioxide was constant at $0.15 \mathrm{mg} / \mathrm{L}$ and chlorite was $0.45 \mathrm{mg} / \mathrm{L}$. According to USEPA (1998), the maximum residual disinfectant level (MRDL) of $0.8 \mathrm{mg} / \mathrm{L}$ and $1.0 \mathrm{mg} / \mathrm{L}$ have been proposed for residual chlorine dioxide and the chlorite in drinking water, respectively. So the chlorite in this study is lower than the critical value of the USEPA.

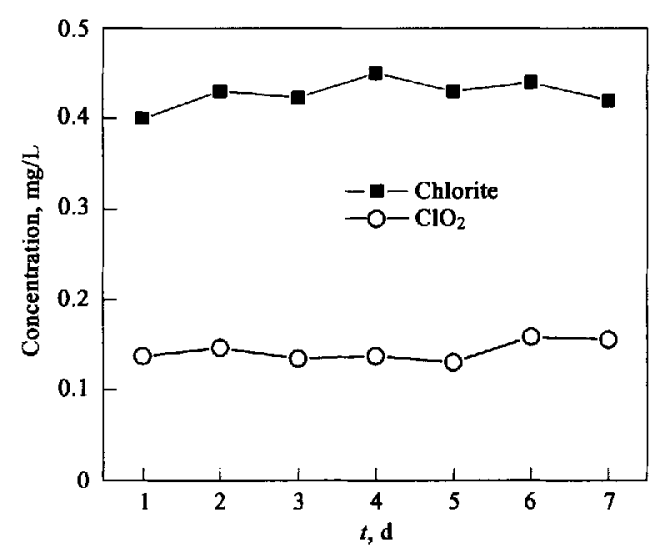

Fig.4 By-products of water after filtration with prechlorine dioxide of $1.0 \mathrm{mg} / \mathrm{L}$

\subsection{Comparison of removal efficiencies of two preoxidation processes}

During the full-scale study, the removal effect on Mesocyclops leukarti by chlorine dioxide preoxidation with $1.0 \mathrm{mg} / \mathrm{L}$ of $\mathrm{ClO}_{2}$ was compared with the existing prechlorination process with $3.0 \mathrm{mg} / \mathrm{L}$ of chlorine (Fig.5)

It can be seen from Fig. 5 that the removal effect of chlorine dioxide preoxidation is better than that of 


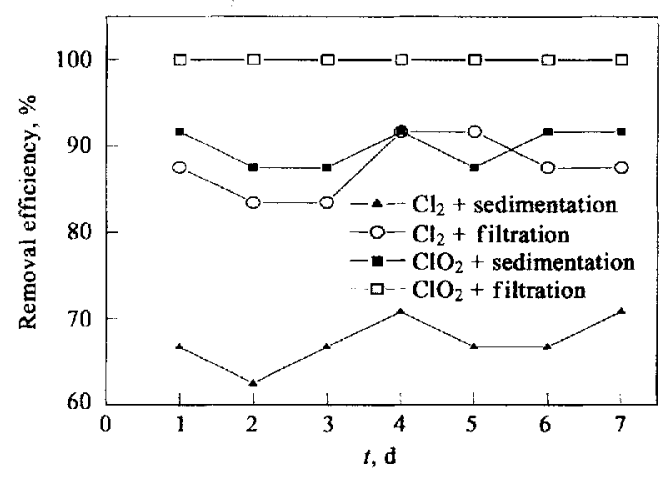

Fig.5 Comparison of the effects on Mesocyclops leukarti removal in two different processes

prechlorination. For instance, Mesocyclops leukarti is fully removed from water by filtration with chlorine dioxide, whereas only $80 \%$ of removal rate is attained with chlorine.

Mature Mesocyclops leukarti is hardly removed from water by sedimentation unless it is effectively inactivated by oxidant. Fig. 5 shows that $90 \%$ of removal rate in treated water after sedimentation is attained by chlorine dioxide preoxidation, but for prechlorination only $65 \%$ is attained. The distinct difference in Mesocyclops leukarti inactivation cfficiency of the two preoxidation processes may be the results of the body structure of Mesocyclops leukarti and the different performance of oxidant in oxidizing cellular tissue.

Compared with common bacteria or virus, Mesocyclops leukarti has a special surface structure consisting of seven layers cell tissue such as bottom membrane, epithelium, calcific layer, and so on. The body surface provides Mesocyclops leukarti stronger protection against oxidation. Mesocyclops leukarti can not be effectively inactivated unless the oxidant destroys its surface structure by oxidation or directly penctrates into its body to oxidize the inner protein. Therefore, higher oxidizability of oxidant is the key to the thorough inactivation of Mesocyclops leukarti. For chlorine in $\mathrm{ClO}_{2}$, oxidation number is expressed as +4 . According to counting, it contains $263 \%$ of available chlorine, i.c. oxidizability of $\mathrm{ClO}_{2}$ is about 2.5 times as high as that of chlorine (Huang et al., 1997). Therefore, the ability of chlorine dioxide to oxidize Mesocyclops leukarti body structure is more effective than that of chlorine. In addition, after dissolving in water, $100 \%$ of $\mathrm{ClO}_{2}$ existing in molecular state does not react with water molecular like chlorine, which makes it casier for $\mathrm{ClO}_{2}$ to contact Mesocyclops leukarti surface and to permeate into its inner body to destroy the inner cellular protein. The above advantages of chlorine dioxide not only result in a better inactivation of Mesocyclops leukarli but also in a lower required amount of it than chlorine.

\subsection{Influence of preoxidation on organic sub-}

\section{stances and mutagenicity}

The GC-MS examination and Ames test were carried out with raw water sample and two treated water samples by preoxidation to evaluate the security of drinking water. The results are shown in Fig.6, and the Ames test results are shown in Table 2.

Table 2 Changes of TA98 and TA100 dose-response relationship

\begin{tabular}{lccc}
\hline Water sample & Dosage, L/plate & TA98 & TA100 \\
\hline Raw water & 1 & 0.71 & 0.98 \\
& 3 & 0.78 & 1.12 \\
& 5 & 0.95 & 1.27 \\
Prechlorination & 7 & 1.34 & 1.53 \\
& 1 & 0.92 & 1.14 \\
& 3 & 1.26 & 1.63 \\
Chlorine dioxide preoxidation & 5 & 2.63 & 2.87 \\
& 7 & 2.95 & 3.18 \\
& 3 & 0.74 & 1.01 \\
& 3 & 0.89 & 1.25 \\
& 5 & 1.04 & 1.38 \\
& 7 & 1.37 & 1.65 \\
\hline
\end{tabular}

\subsubsection{GC-MS examination}

From Fig.6, it can be seen that the amount of organic substance decreased to 41 species by chlorine dioxide preoxidation, which was equal to $57.7 \%$ of that in raw water and $53.9 \%$ of that water treated by prechlorination. In addition, $85.4 \%$ of species were low boiling point and micromolecule organic substances and the number of halogenated hydrocarbon was only 3 species in water treated by chlorine dioxide preoxidation.

The different reaction mechanisms of the organic substances which react with chlorine dioxide and chlorine cause the diverse results in GC-MS examination. The free radical oxidation reaction happens when chlorine dioxide reacts with organic substances. The macromolecule organic compounds are oxidized into micromolecule substances, in which some volatile compounds, even $\mathrm{CO}_{2}$ and $\mathrm{H}_{2} \mathrm{O}$ are formed (Benjamin et al., 1986). Moreover, the stronger oxidizability of chlorine dioxide may easily oxidize organic substance to such products with low boiling point and minor molecular weight, which have shorter retention time in GS-MS examination. But for chlorine, the electrophilic substitution reaction results in the formation of more mutagenic halogenated hydrocarbon such as trichloromethane, which belongs to high boiling point and macromolecule organic compounds with long retention time (Reckhow et al., 1990; Langvik and Holmbom, 1994). In addition, many intermediate products such as aldehyde may bc produced during chlorination due to no thoroughly oxidizing organic substances with chlorinc. The 

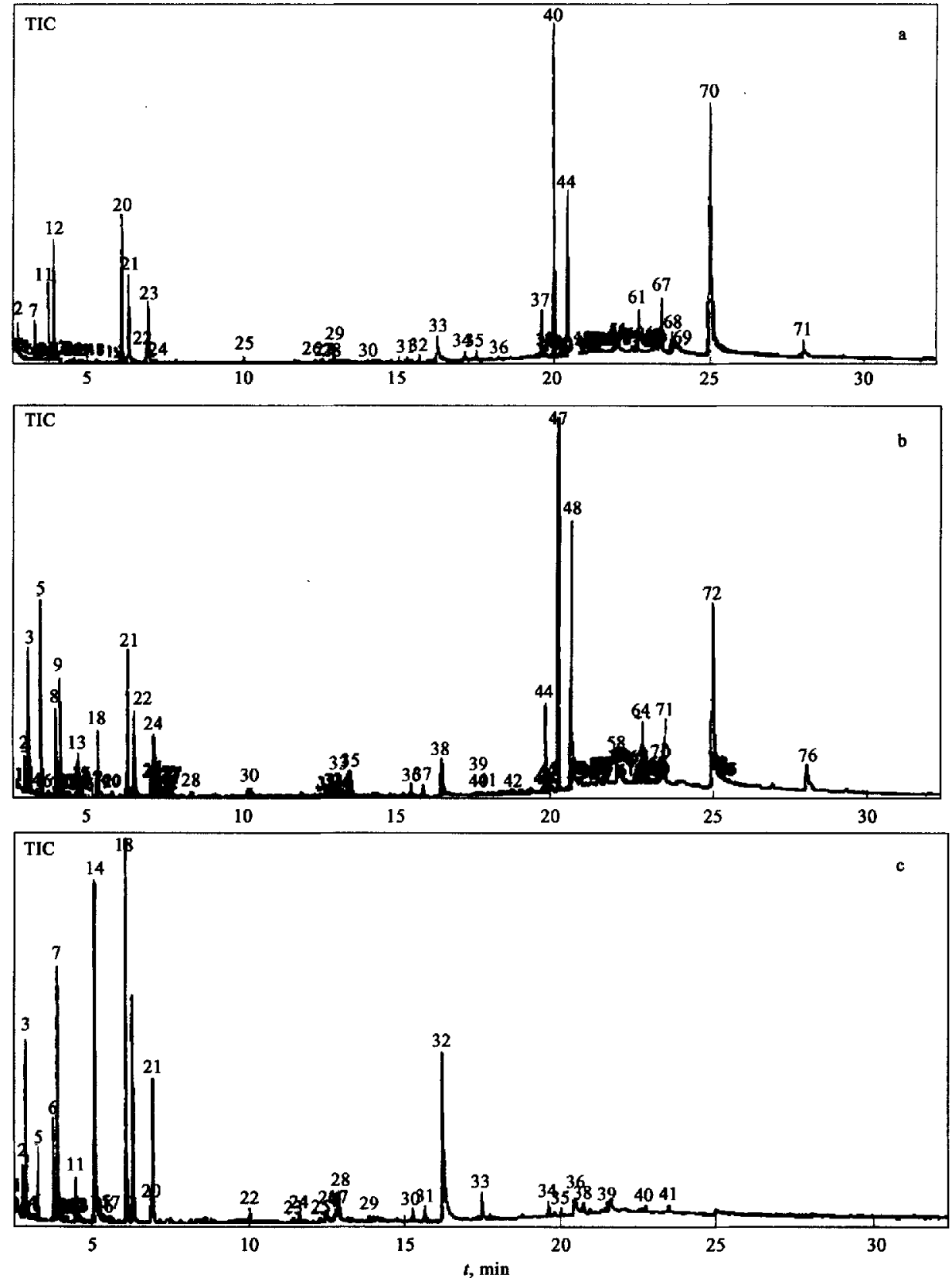

Fig.6 Graphic of total organic ions of raw water (a), water sample by prechlorination (b) and water sample by chlorine dioxide preoxidation (c)

results are that the total amount of organic substance by prechlorination is more than that treated by chlorine dioxide preoxidation. Therefore, it can be concluded that the drinking water quality by chlorine dioxide preoxidation is better than that of prechlorination.

\subsubsection{Ames test}

The mutagenic activity of chlorinated drinking water has been shown in numerous studies (Schenck et al., 1998). In this study the results of Ames test are shown in Table 2 . The mutagenicity of concentrated water samples before and after preoxidation is expressed as MR value. It is considered as having mutagenic activity when MR value larger than 2
(Maron and Ames, 1984).

The MR value of raw water has not mutagenic activity under any dose condition. The MR value of water sample by prechlorination is higher than that by chlorine dioxide preoxidation at the same doses. $\mathrm{Cl}_{2}$-treated water showed mutagenicity with TA98 strain $(M R=2.63)$ and TA100 strain $(M R=2.87)$ at lower doses (5 L equivalent/plate), whereas $\mathrm{ClO}_{2}$-treated water has a lower mutagenic activity. The MR value with TA98 and TA100 are 1.37 and 1.65 respectively detectable at the highest doses $(7 \mathrm{~L}$ equivalent/plate). 13 species of halogentated compounds were formed during prechlorination due to the electrophilic substitution reaction between 
chlorine and organic substances. And the special chemical active group of them, halogen with stronger electrophonic effect, reinforces molecule polarity to react with biologic enzyme system, while the mutagenic action is attained by a series of chemical reactions such as DNA base substitution etc. (Langvik and Holmbom, 1994). During chlorine dioxide preoxidation, less halogentated compounds (only one species) are formed due to different reaction mechanism. Hence, mutagenicity of $\mathrm{ClO}_{2}$-treated water is obviously lower than that of $\mathrm{Cl}_{2}$-treated, which is supported by some previous Ames test results (Fiessinger, 1991; Huang and Li, 1998).

It is worth noting that the mutagenicity of $\mathrm{ClO}_{2}$-treated water is a little higher than that of raw water. The results may be caused by impurities chlorine ( $7.4 \%$ of the total chlorine dioxide) produced by our generator (Table 1). The advantage of chlorine dioxide disinfection may be further improved by enhancing chlorine dioxide gas purity.

\section{Conclusions}

In summary, the following conclusions can be achieved:

(1) Chlorine dioxide has the good inactivation effect on Mesocyclops leukarti. 100\% inactivate rate of Mesocyclops leukartican be obtained with $1.5 \mathrm{mg} / \mathrm{L}$ of chlorine dioxide contacting for $30 \mathrm{~min}$ in lab;

(2) Higher oxidizability of chlorine dioxide is the key to the inactivation of Mesocyclops leukarti. 100\% of $\mathrm{ClO}_{2}$ existing in molecular state does not react with water molecular like chlorine, which makes it easier for $\mathrm{ClO}_{2}$ to contact Mesocyclops leukarti surface and to permeate into its inner body.

(3) In full-scale study, 100\% of removal effect on treated water from the sand filter can be attained by $1.0 \mathrm{mg} / \mathrm{L}$ of $\mathrm{ClO}_{2}$. Mesocyclops leukarti can be effectively removed from water by chlorine dioxide preoxidation cooperating with the conventional clarification process.

(4) The chlorite, a by-product of $\mathrm{ClO}_{2}$, is stable at $0.45 \mathrm{mg} / \mathrm{L}$ after filtration, which is lower than the critical value of USEPA.

(5) The GC-MS examination showed that the sort and amount of organic substances in treated water by chlorine dioxide preoxidation were evidently less than that of prechlorination, and the mutagenicity of drinking water is highly reduced.

\section{References:}

Aicta F M, Berg J D, 1986. A view of chlorine dioxide in drinking water treatment[J]. Journal of AWWA, 78(6): 62-73.

Benjamin W, Lukins J, Mark H G, 1986. Using chlorine dioxide for trihalomethane control[J]. Journal of AWWA, 78(6): 88-93.
Bernhardt H, Lusse B, 1989. Elimination of zooplankton by flocculation and filtration[J]. Journal of Wat Supp: Res \&Technol-AQUA, 38 (1): $23-31$.

Chinese EPA, 1997. Water and wastewater monitoring methods[M]. 3rd ed. Beijing: Chinese Environmental Science Publishing House. $120-126$

Cui $F$ Y, Lin T, Ma F, 2002. The excess propagation and research on ecological control of the water flea of cooplankton in raw water [J]. Journal of HIT, 34(3): 399--403.

Fiessinger $\mathrm{F}, 1991$. Advantages and disadvantages of chemical oxidation and disinfection of ozone and chlorine dioxide [J]. Sci of the Total Environ, 18: 245-246.

Gibbona J, Laha S, 1999. Water purification systems: a comparative analysis based on the occurrence of disinfection by-products [.J. Environ Pollu, 106(3): 425-428

Haider T, Sommer R, Knasmuller S et al., 2002. Genotoxic response of Austrian groundwater samples treated under standardized UV $(254 \mathrm{~nm})$ disinfection conditions in a combination of three different bioassays[J]. Wat Res, 36 (1): $25-32$.

Huang J L, Wang L, Ren N Q, 1997. Disinfection effect of chlorine dioxide on viruses, algae and animal plankton in water [J]. Watt Res, 31(3): 455-460.

Huang J L, Li B X, 1998. Comparison of the mutagenicity of drinking water with chlorine dioxide and chlorine disinfections [J]. Environ Chem, 17(4): 34-38.

Langvik V, Holmbom B, 1994. Formation of mutagentic organic byproducts and aox by chlorination of fractions of humic water [J]. Wat Res, 28 (3): 553-557.

Li J W, Yu Z, Cai X ol oll., 1996. Trihalomethanes formation in water treated with chlorine dioxide[J]. Wat Res, 30(10): 2371-2376.

Lupi E, Ricci V, Burrini D, 1994. Occurrence of nematodes in surface water used in a drinking water plant[J]. Journal of Wat Supp Res Technol, 43(3): 107-112.

Lykins B W, Griese M H, 1986. Using chlorine dioxide for trihalomethane control [J]. Journal of AWWA, 79(7): 125-133.

Ma J, Liu W, 2002. Effectiveness and mechanism of potassium ferrate (VI) preoxidation for algae removal by coaulation $[\mathrm{J}]$. Wat Res, 36(4): $871-878$.

Maron D M, Ames B N, 1984. Revised methods for the Salmonella mutagenicity test $[\mathrm{M}]$. In: Handbook of mutagenicity test procedures (Kilbey B $e t$ al., ed.). New York: Elsevier. 93-140.

Mitcham R P, Shelley M W, Wheadon C M, 1983. Free chlorine versus ammonia-chlorinc: disinfection, trihalomethane formation, and zooplankton removal[1]. Joumal of AWWA, 75(4): 196-198.

Narkis N, 1995. Disinfection of efficient by combinations of chlorine dioxide and chlorine[J]. Wat Sci Technol, 31(5): 105-114.

Olajide I, Sridhar M K, 1987. Guineaworm control in an endemic area in western Nigeria [J]. Journal of Wat Supp: Res \& Technol-AQUA, 6: 333-339.

Reckhow D A, Singer P C, Malcolm R L, 1990. Chlorination of humic materials: byproduct formation and chemical interpretations $[\mathrm{J}]$. Environ Sci Technol, 24(11): 1655-1664.

Schenck K M, Wymer L J, Lykins B W et al. 1998. Application of a Finnish mutagenicity model to drinking water in the U.S. [J]. Chemosphere, 37(3): 451-464.

USEPA, 1983. Interim procedures for conducting the Sidmonellal microsomal mutagenicity assay-Ames test [S]. EPA/600/4 83/013, US Environmental Protection Agency, Cincinnati, Ohio.

USEPA, 1998d. National primary drinking water regulations disinfectants and disinfection byproducts: final rule [S]. 40 CFR Parts 9, 141\&142, FED. Reg. 63 No. 241, Dec.16, pp. 6939069476

Xing H, 2004. The removal of Cyctops in water treatment process $|J|$. China Water and Wastewater, 20(7): 88

(Received for review November 11, 2005. Accepted March 1, 2006) 